\section{F Scale}

Richard Temple

Clinical Operations, CORE Health Care,

Dripping Springs, TX, USA

\section{Synonyms}

Frequency scale; Infrequency scale

\section{Definition}

Validity scale on the Minnesota Multiphasic Personality Inventory (MMPI) and its revisions designed to detect unusual approaches to answering test items. The scale is comprised of items endorsed by no more than $10 \%$ of an early sample of respondents. Items represent unlikely or contradictory beliefs, expectations, or selfdescriptions (Dahlstrom et al. 1972). The majority of items are unique to this scale, although some overlap with scales 6 (paranoia) and 8 (schizophrenia). Profiles with extreme scores are generally deemed invalid, as the individual may be significantly compromised or psychotic, although the research on cutoff scores is somewhat inconsistent. Within the realm of neuropsychological evaluation, moderately elevated scores may indicate awareness of neurological compromise and a "cry for help" regarding these difficulties. Readers are referred to the MMPI entry for a discussion of limitations of this self-report measure when used with neuropsychological populations (Gass 2006; Lezak et al. 2004).

\section{Cross-References}

- F Minus K Index

$\checkmark$ Fake Bad Scale

Faking Good, Bad

- K Scale

$\rightarrow$ L Scale

- Minnesota Multiphasic Personality Inventory

- True Response Inconsistency Scale (TRIN, MMPI)

- Validity Scales (MMPI)

- Variable Response Inconsistency Scale (VRIN, MMPI)

\section{References and Readings}

Dahlstrom, W. G., Welsh, G. S., \& Dahlstrom, L. E. (1972). An MMPI handbook: Vol. 1. Clinical interpretation. Minneapolis: University of Minnesota Press.

Gass, C. (2006). Use of the MMPI-2 in neuropsychological evaluations. In J. Butcher (Ed.), MMPI-2: A practitioner's guide (pp. 301-326). Washington, DC: American Psychological Association.

Lezak, M. D., Howieson, D. B., Bigler, E. D., \& Tranel, D. (2012). Neuropsychological assessment (5th ed.). New York: Oxford University Press. 